\title{
Protein modifications related to phage resistance in a marine roseobacter
}

\author{
Yongyu Zhang ${ }^{1,2}$, Nianzhi Jiao ${ }^{2, *}$, David R. Colquhoun ${ }^{3}$, Rolf U. Halden ${ }^{3,4}$, \\ Feng Chen ${ }^{1, * *}$ \\ ${ }^{1}$ Center of Marine Biotechnology, University of Maryland Biotechnology Institute, Baltimore, Maryland 21202, USA \\ ${ }^{2}$ State Key Laboratory of Marine Environmental Science, Xiamen University, Xiamen, 361005, PR China \\ ${ }^{3}$ Department of Environmental Health Sciences, Center for Water and Health, Johns Hopkins Bloomberg School of Public \\ Health, Baltimore, Maryland 21205-2179, USA \\ ${ }^{4}$ Center for Environmental Biotechnology, The Biodesign Institute at Arizona State University, Tempe, \\ Arizona 85287-5701, USA
}

\begin{abstract}
The Roseobacter lineage is an important group of bacteria in the marine environment. Silicibacter pomeroyi DSS-3 has been used as a model strain for understanding the biological and ecological relevance of this group. Recently, a phage $(\Phi 1)$ which infects $S$. pomeroyi DSS-3 was isolated in our laboratory. Mutants of DSS-3 that are resistant to phage $\Phi 1$ were also obtained. A comparison of the protein expression profiles of the wild type, DSS-3, and the phage $\Phi 1$-resistant mutant M1 identified a potential phage resistance response due to the modification of 4 highly expressed proteins. One of these 4 proteins was successfully identified via mass spectrometry, and matched a hypothetical protein (SPOA0343) in the S. pomeroyi DSS-3 genome. Although the type of protein modification has not yet been determined, our results suggest that bacteria could become resistant to phage infection via protein modification. Studies on phage resistance of $S$. pomeroyi DSS-3 could provide new insight into the complex relationship between marine bacteria and their viruses in the natural environment.
\end{abstract}

KEY WORDS: Silicibacter pomeroyi DSS-3 · Phage resistance $\cdot$ Two-dimensional polyacrylamide gel electrophoresis $\cdot$ Mass spectrometry $\cdot$ Protein modification

\section{INTRODUCTION}

Viruses are the most abundant biological entities $\left(\sim 10^{30}\right)$ in the sea (Fuhrman 1999, Suttle 2007), and natural marine viral communities are usually dominated by phages (Weinbauer 2004). They can infect and lyse prokaryotic cells and, by so doing, influence microbial food web processes, biogeochemical cycles, and the structure of microbial communities (Fuhrman 1999, Wilhelm \& Suttle 1999, Bohannan \& Lenski 2000, Weinbauer 2004, Mann 2005, Suttle 2005). Meanwhile, prokaryotic cells are also able to defend themselves against phages by deploying anti-phage mechanisms. Bacteria are able to gain resistance to phages via various mechanisms, including (1) adsorption inhibition due to changes in receptors utilized by the phages for infection; (2) DNA penetration blocking; (3) restriction/modification; and (4) abortive infection (Hill 1993, Allison \& Klaenhammer 1998, Weinbauer 2004). Recently, another novel counter-infection approach based on clustered regularly interspaced short palindromic repeats (CRISPRs) in the bacterial genome was discovered (Barrangou et al. 2007, Horvath et al. 2008). The ongoing 'arms race' between phage infection and 
host defense has important consequences for their coevolution by directional selection (Buckling 2002).

The Roseobacter lineage is widely distributed in various marine environments and represents one of the most abundant bacterial populations in the sea (Buchan et al. 2005, Wagner-Döbler \& Biel 2006). Members of the Roseobacter are important to the ocean's carbon and sulfur cycles (Gonzalez et al. 2003, Moran et al. 2003, Buchan et al. 2005, Wagner-Döbler \& Biel 2006, Moran et al. 2007). Many studies have been performed on the roseobacters, but little is known about their phages and few have been isolated (Rohwer et al. 2000, Zhang \& Jiao 2009, Zhao et al. 2009). The interaction between roseobacters and their phages is poorly understood.

Silicibacter pomeroyi DSS-3, isolated from coastal water off Georgia, USA, is a member of the Roseobacter lineage (Gonzalez et al. 2003). It serves as a model system for studying the ecophysiological traits of marine roseobacters. The genome sequence of DSS-3 indicates that $S$. pomeroyi is involved in several important processes, including carbon monoxide oxidation, sulfur-based reactions, aromatic compound degradation and secondary metabolite production (Moran et al. 2004). Thus, studies on DSS-3 could provide important insights into this organism's ecological role. Recently, a lytic phage $(\Phi 1)$ from Chesapeake Bay, USA, which infects $S$. pomeroyi DSS-3, was isolated in our laboratory. In addition, mutant strains of DSS-3 that are resistant to phage $\Phi 1$ were also obtained.

To learn what kind of changes at the protein level enable DSS-3 to become resistant to the infection of phage $\Phi 1$ we applied 2D gel-based proteomics to compare the total protein profiles between the wild type (DSS3) and a phage ( $\Phi 1$ ) resistant mutant strain (M1). We demonstrated that proteomics is a useful tool for investigating bacterial anti-phage mechanisms. To the best of our knowledge, this work constitutes the first application of comparative proteomics to the study of phage resistance.

\section{MATERIALS AND METHODS}

Silicibacter pomeroyi DSS-3 was kindly provided by M. A. Moran at the University of Georgia and grown in YTSS medium (4 $\mathrm{g} \mathrm{l}^{-1}$ yeast extract, $5 \mathrm{~g} \mathrm{l}^{-1}$ Tryptone, $20 \mathrm{~g} \mathrm{l}^{-1}$ sea salt, and distilled water) at room temperature (ca. $25^{\circ} \mathrm{C}$ ). Phage $\Phi 1$, which infects DSS-3, was obtained by challenging the DSS-3 cultures against the viral concentrates (5 to $10 \mathrm{ml}$ ) collected from Chesapeake Bay. Phage $\Phi 1$ was clonally isolated using the plaque assay (Adams 1959). The lysate of phage $\Phi 1$ was purified using the $\mathrm{CsCl}$ density gradient ultracentrifugation method as previously described by
Chen et al. (2006). The morphological feature of phage $\Phi 1$ was observed by transmission electron microscopy (TEM).

To isolate the phage resistant strains, the DSS-3 culture was incubated with a high titer of phage $\Phi 1$ (Kemp et al. 1993). Briefly, $1 \mathrm{ml}$ of early exponentially growing DSS-3 (ca. $2 \times 10^{8}$ cells ml ${ }^{1}$ ) was incubated with $200 \mu \mathrm{l}$ of high titer phage $\Phi 1$ lysate $\left(10^{10}\right.$ plaqueforming units [PFU] $\mathrm{ml}^{-1}$ ) for $30 \mathrm{~min}$, and plated out using a plaque assay. No growth of bacteria was evident in the first few days of incubation, compared to the control (DSS-3 with no phage added). Some bacterial colonies appeared after $1 \mathrm{wk}$, and these bacterial colonies were picked and clonally purified again. The mutant M1 examined here is one of the phage $\Phi 1$ resistant strains.

To obtain the growth curves of wild type DSS-3 and mutant M1, both cultures were incubated in liquid YTSS medium at $25^{\circ} \mathrm{C}$ with a shaking speed of $200 \mathrm{rpm}$. Subsamples were obtained at $2 \mathrm{~h}$ intervals and absorption was determined at a wavelength of $600 \mathrm{~nm}$ using a spectrophotometer (Smartspec ${ }^{\mathrm{TM}}$ Plus, Bio-Rad). Proteins were extracted from the exponentially growing DSS-3 and M1 cells at an optical density $\left(\mathrm{OD}_{600}\right)$ of $\sim 1.0$ and analyzed using the 2D polyacrylamide gel electrophoresis (2D-PAGE) following the protocols previously described by Kan et al. (2005). A total of $150 \mu \mathrm{g}$ of protein from each culture was used for the 2D-PAGE analysis. The proteins were separated on $\mathrm{pH} 4$ to 7 immobilized $\mathrm{pH}$ gradient strips $(11 \mathrm{~cm})$, followed by 8 to $16 \%$ gradient precast polyacrylamide gels. The gels were stained with SYPRO Ruby and imaged using a Typhoon 9410 Imager. Analysis of the gels was accomplished using ImageMaster 2D Platinum 5.0 software. Finally, the differentially expressed protein spots were manually excised from gels and identified via Matrix-assisted laser desorption/ionization time-of-flight mass spectrometry (MALDI-TOF MS) as described by Kan et al. (2005).

\section{RESULTS AND DISCUSSION}

Phage $\Phi 1$ is a lytic phage that infects Silicibacter pomeroyi DSS-3 and forms small, clear, round plaques (ca. 1 to $2 \mathrm{~mm}$ in diameter) on the bacterial lawn. Phage $\Phi 1$ has an isometric head (ca. $70 \mathrm{~nm}$ in diameter) and a long, flexible, non-contractile tail (ca. $142 \mathrm{~nm}$ long) (Fig. 1). It contains double-stranded DNA and has a genome size of $63.5 \mathrm{~kb}$ (data not shown). Phage $\Phi 1$ belongs to the family Siphoviridae.

Upon superinfection, phage $\Phi 1$ was able to kill nearly all the host cells, thus turning the plate clear. Several surviving colonies were observed on the plate 1 wk after the infection. These phage-resistant 


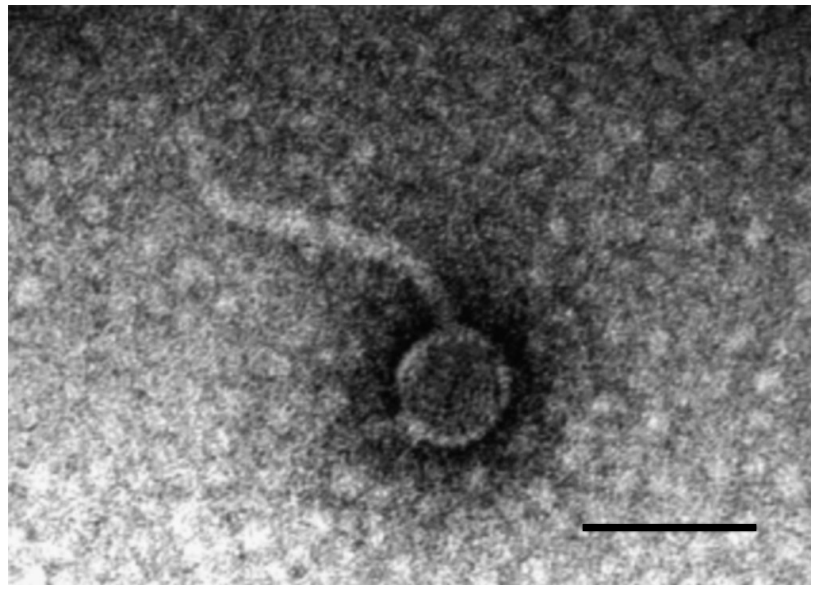

Fig. 1. Transmission electron microscopy (TEM) image of roseophage $\Phi 1$. Scale bar $=100 \mathrm{~nm}$

mutants were isolated and purified, and mutant M1 was picked for further study. After transferring M1 for at least 100 generations, it was still resistant to phage $\Phi 1$, suggesting the occurrence of an enduring mutation in the host cell, rather than a mere physiological response. Meanwhile, the heritable nature of phage resistance suggested that the anti-phage mechanism of M1 was unlikely to be abortive infection, since abortive-type defenses usually result in the destruction of the host cells (Weinbauer 2004).

Obtaining resistance to phages is often accompanied by a decrease in the competitive ability of the bacterial cell (Bohannan et al. 2002). Most phage-resistant mutants achieve phage resistance through the loss or modification of the receptor molecules on the cell surface (Lenski 1988), which are often involved in aspects of bacterial metabolism such as the uptake of nutrient sources. Thus, gaining resistance to phages frequently comes at the expense of a reduced competitiveness of the host bacterium (Lenski 1988). Interestinlgy, DSS-3 and M1 showed nearly identical growth curves (Fig. 2), indicating that the growth rate of DSS-3, when incubated in the YTSS medium, was not reduced after becoming resistant to phage $\Phi 1$. It is worth noting that the cost of phage resistance can usually be influenced by environmental parameters. For example, a phageresistant mutant cultured in varied growth-limiting resources may encounter different degrees of reduction in competitiveness. A nutrition-rich resource can usually partially offset the cost of phage resistance of a cell (Bohannan et al. 2002). Additional studies are still needed in order to understand the competitiveness of a phage-resistant bacterium like M1 under different growth conditions.

Using the 2D-PAGE method, we compared the proteomes of DSS-3 and M1 during the same growth

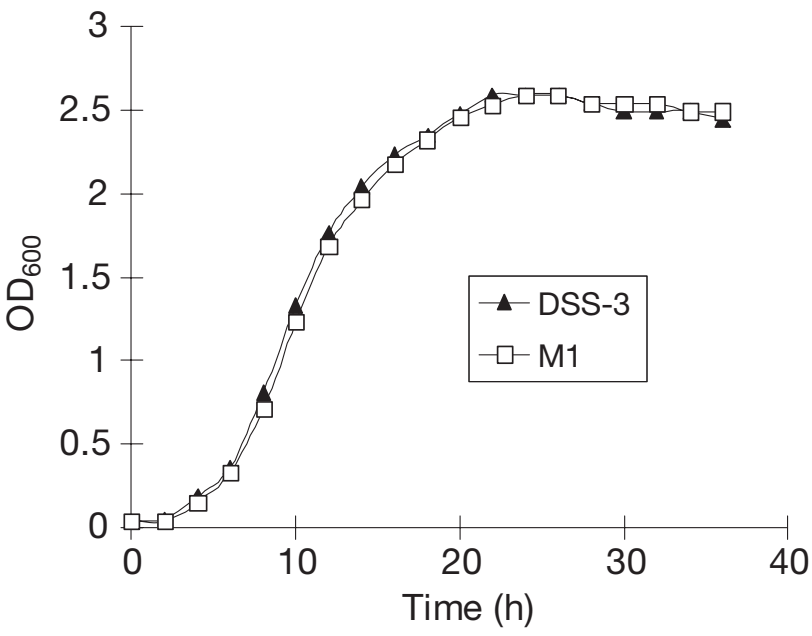

Fig. 2. Silicibacter pomeroyi. Growth curves of the wild type DSS-3 and its phage-resistant mutant M1. DSS-3 and M1 were incubated synchronously in YTSS medium at $25^{\circ} \mathrm{C}$, with a shaking speed of $200 \mathrm{rpm}$. $\mathrm{OD}_{600}$ : optical density at a wavelength of $600 \mathrm{~nm}$

phase incubated under the same condition. Remarkably, we found that 4 additional proteins were overexpressed in M1 as compared to DSS-3 (shown in the circled area of Fig. 3), while all other proteins of the 2 bacteria nearly completely matched. The 4 'shifted' proteins shared similar molecular weights with their parental proteins, but their isoelectric points (pI) moved towards the alkaline spectrum (from pI 4.9 to $\mathrm{pI}$ 5.0). The protein spot ' $a$ ' and its parental protein spot 'A' were identified as the same protein, matching the hypothetical protein SPOA0343 from DSS-3 (NCBI accession no. GI56709125). The other 3 proteins below spot 'A' were not characterized successfully, probably due to the relatively lower yield of proteins or a contamination issue. Regardless, our result suggests that modifications of hypothetical protein SPOA0343, and perhaps those 3 uncharacterized proteins, are likely involved in the phage resistance processes. Whether such a protein modification is phage-specific or a general response to other environmental stresses deserves further studies.

Covalent modifications to protein structures occurring either co- or posttranslationally are an important component of protein regulation and function. Over 200 different modifications have been described (Krishna \& Wold 1993). Many, such as phosphorylation and dephosphorylation, have well-documented roles in signal transduction and the regulation of cellular processes (Krishna \& Wold 1993). Dephosphorylation can shift the protein $\mathrm{pI}$ to the more alkaline spectrum. The type of protein modification for these 4 proteins in the phage-resistant mutant M1 has not been characterized yet and remains to be investigated. 
pI 4

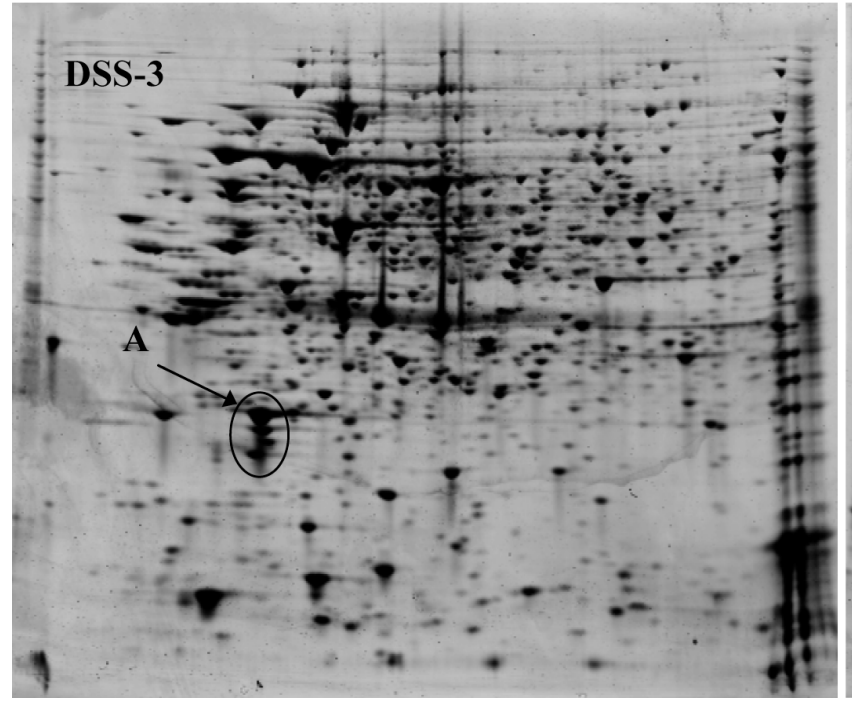

pI 7 pI 4

pI 7

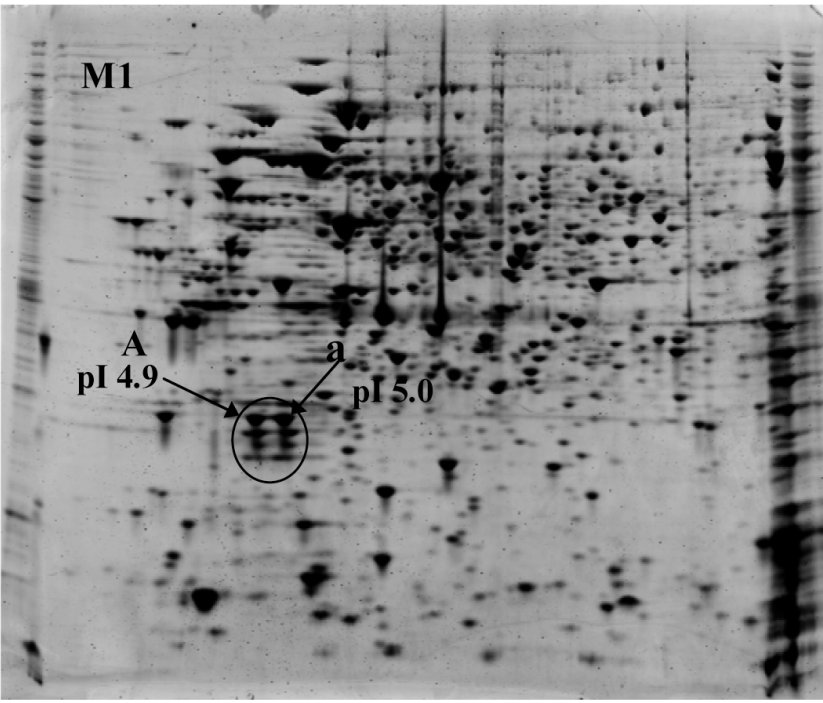

Fig. 3. Silicibacter pomeroyi. Protein expression profiles of wild type DSS-3 (left panel) and mutant M1 (right panel). The major differentially expressed proteins are shown in circles. Spot 'A' (with isoelectric point $[\mathrm{pI}]=4.9$ ) and spot 'a' (with $\mathrm{pI}=5.0$ ) were identified as the same protein based on MALDI-TOF MS analysis

This exploratory study demonstrates that comparative proteomics is a powerful tool for studying phage resistance in bacteria. Our results indicate that bacteria may gain resistance to phage infection via the modification of translational proteins. It would be interesting to explore whether such a phage-defense mechanism commonly exists among roseobacters or other bacteria.

Acknowledgements. We thank Y. L. Zhao for providing Phage $\Phi 1$ and a TEM image. We acknowledge funding support from the National Science Foundation's Microbial Observatories Program (MCB-0132070, MCB-0238515, MCB-0537041 to F.C.), and the funds from the Xiamen University 111 program to F.C. and 2007 CB815904 to N.Z.J. Professor John Hodgkiss is thanked for help with English.

\section{LITERATURE CITED}

Adams MH (1959) Bacteriophages. Interscience Publishers, Inc, New York

Allison GE, Klaenhammer TR (1998) Phage resistance mechanisms in lactic acid bacteria. Int Dairy J 8:207-226

- Barrangou R, Fremaux C, Deveau H, Richards M and others (2007) CRISPR provides acquired resistance against viruses in prokaryotes. Science 315:1709-1712

Bohannan BJM, Lenski RE (2000) Linking genetic change to community evolution: insights from studies of bacteria and bacteriophage. Ecol Lett 3:362-377

Bohannan BJM, Kerr B, Jessup CM, Hughes JB, Sandvik G (2002) Trade-offs and coexistence in microbial microcosms. Anton Leeuwenhoek 81:107-115

- Buchan A, Gonzalez JM, Moran MA (2005) Overview of the marine Roseobacter lineage. Appl Environ Microbiol 71: 5665-5677
Buckling A (2002) Antagonistic coevolution between a bacterium and a bacteriophage. Proc R Soc Lond B Biol Sci 269:931-936

> Chen F, Wang K, Stewart J, Belas R (2006) Induction of multiple prophages from a marine bacterium: a genomic approach. Appl Environ Microbiol 72:4995-5001

Fuhrman JA (1999) Marine viruses and their biogeochemical and ecological effects. Nature 399:541-548

Gonzalez JM, Covert JS, Whitman WB, Henriksen JR and others (2003) Silicibacter pomeroyi sp. nov. and Roseovarius nubinhibens sp. nov., dimethylsulfoniopropionatedemethylating bacteria from marine environments. Int $\mathrm{J}$ Syst Evol Microbiol 53:1261-1269

Hill C (1993) Bacteriophage and bacteriophage resistance in lactic acid bacteria. FEMS Microbiol Rev 12:87-108

> Horvath P, Romero DA, Coute-Monvoisin AC, Richards M and others (2008) Diversity, activity, and evolution of CRISPR loci in Streptococcus thermophilus. J Bacteriol 190:1401-1412

> Kan J, Hanson TE, Ginter JM, Wang K, Chen F (2005) Metaproteomic analysis of Chesapeake Bay microbial communities. Saline Systems 1:7

Kemp PF, Sherr BF, Sherr EB, Cole JJ (1993) Handbook of methods in aquatic microbial ecology. Lewis Publishers, Boca Raton, FL, p 122-125

> Krishna RG, Wold F (1993) Post-translational modifications of proteins. Adv Enzymol Relat Areas Mol Biol 67:265-298

> Lenski RE (1988) Experimental studies of pleiotropy and epistasis in Escherichia coli. I. Variation in competitive fitness among mutants resistant to virus T4. Evolution 42: $425-432$

Mann NH (2005) The third age of phage. PLoS Biol 3(5):e182

> Moran MA, González JM, Kiene RP (2003) Linking a bacterial taxon to sulfur cycling in the sea: studies of the marine Roseobacter group. Geomicrobiol J 20:375-388

> Moran MA, Buchan A, Gonzalez JM, Heidelberg JF and others (2004) Genome sequence of Silicibacter pomeroyi reveals adaptations to the marine environment. Nature 432:910-913 
Moran MA, Belas R, Schell MA, González JM and others (2007) Ecological genomics of marine roseobacters. Appl Environ Microbiol 73:4559-4569

Rohwer F, Segall A, Steward G, Seguritan V, Breitbart M, Wolven F, Azam F (2000) The complete genomic sequence of the marine phage Roseophage SIO1 shares homology with nonmarine phages. Limnol Oceanogr 45:408-418

Suttle CA (2005) Viruses in the sea. Nature 437:356-361

Suttle CA (2007) Marine viruses-major players in the global ecosystem. Nat Rev Microbiol 5:801-812

Wagner-Döbler I, Biebl H (2006) Environmental biology of the marine Roseobacter lineage. Annu Rev Microbiol 60:

Editorial responsibility: Gunnar Bratbak,

Bergen, Norway
$255-280$

Weinbauer MG (2004) Ecology of prokaryotic viruses. FEMS Microbiol Rev 28:127?181

Wilhelm SW, Suttle CA (1999) Viruses and nutrient cycles in the sea. Bioscience 49:781?788

Zhang Y, Jiao NZ (2009) Roseophage RDJL ${ }^{\circ}$, infecting the aerobic anoxygenic phototrophic bacterium Roseobacter denitrificans OCh114. Appl Environ Microbiol 75: 1745-1749

Zhao YL, Wang K, Jiao NZ, Chen F (2009) Genome sequences of two novel phages infecting marine roseobacters. Environ Microbiol (in press)

Submitted: December 10, 2008; Accepted: March 23, 2009

Proofs received from author(s): April 27, 2009 